\title{
Mineral Sources
}

National Cancer Institute

\section{Source}

National Cancer Institute. Mineral Sources. NCI Thesaurus. Code C112949.

Indicates that a product is derived from a specified mineral material. 